\title{
Música Popular y Contracultura: Jaime Guevara el cantor de contrabando
}

\section{Popular Music and Contraculture: Jaime Guevara the contraband singer}

\section{Música Popular e Contracultura: Jaime Guevara, o cantor contrabando}

\author{
Jorge Campos Serrano ${ }^{1}$ \\ Centro de Investigaciones Musicales de la UDH C.I.M. (Ecuador) \\ jecamposs@profesores.uhemisferios.edu.ec
}

Fecha de recepción: 20 de agosto de 2019

Fecha de recepción evaluador: 5 de septiembre de 2019

Fecha de recepción corrección: 15 de octubre de 2019

\begin{abstract}
Resumen
El presente artículo está consagrado a uno de los personajes de la escena musical ecuatoriana el cantautor Jaime "Chamo" Guevara, que se ha convertido prácticamente

\footnotetext{
1 Jorge Campos Serrano: Compositor y musicólogo ecuatoriano. Graduado del Conservatorio Tchaikovsky de Moscú (Doctorado en composición musical en 1994, Master en composición musical y musicología en 1992) y de la Universidad París IV Sorbona (Master en musicología del siglo XX en el 2000). Miembro fundador del Theremin Center, centro dedicado a la creación, la investigación y la difusión de la música contemporánea y electroacústica en Rusia entre 1993 Y 1999. Jorge Campos ha recibido encargos de la Unión de Compositores y del Ministerio de Cultura de Rusia, del Museo de Arte Contemporáneo de Moscú, del Centre d'Etudes et de Recherche Pierre Schaeffer de París, del Ensemble Orquestal de París, del grupo CLSI, del ensemble americano Seattle Chamber Players, entre otros. https://orcid.org/0000-0002-0810-0191
} 
en una especie de símbolo, de ícono, de faro de la cultura ecuatoriana y evidentemente de la contracultura, representante por excelencia de la trova urbana, su popularidad se debe a sus canciones muy particulares, que abarcan géneros musicales como el rock, el blues, el country, llegando prácticamente a abordar también el universo musical de la música folclórica, entre otras. No podemos olvidar de hablar sobre su posición de artista comprometido y activista, a través de sus posicionamientos político-culturales y sobre todo su actitud como activo defensor de los derechos humanos, abiertamente declarado en contra de todo tipo de violencia, y lo más trascendente en su ponencia estético-musical es su constante crítica al poder dominante, al poder de turno, con sus fuertes dosis de humor terriblemente urticantes.

Palabras clave: música popular, contracultura, Jaime Guevara, artivismo, trova urbana.

\begin{abstract}
This article is dedicated to one of the personalities of the Ecuadorian musical scene, the singer-songwriter Jaime "Chamo" Guevara. Guevera has practically become a symbol and icon, a lighthouse of the Ecuadorian culture and counterculture, and a representative par excellence of the urban trova. His popularity is due to his very particular songs, which cover diverse musical genres such as rock, blues, country, and which also covers the musical universe of folk music, among others. We cannot forget to mention his politics as a committed artist and activist, through his political-cultural positions and his active defense of human rights. Guevara openly stands against all types of violence. Through strong doses of urticant humor, he constantly confronts dominant power.
\end{abstract}

Key words: popular music, counterculture, Jaime Guevara, artivism, urban trova.

\title{
Resumo
}

Este artigo é dedicado a uma das personalidades da cena musical equatoriana, o cantor e compositor Jaime "Chamo" Guevara. Guevera praticamente se tornou um símbolo e ícone, um farol da cultura e contracultura equatoriana e um representante por excelência da trova urbana. Sua popularidade se deve a suas músicas muito particulares, que abrangem diversos gêneros musicais, como rock, blues, country, e que também abrange o universo musical da música folclórica, entre outros. Não podemos esquecer de mencionar sua política como artista e ativista comprometido, através de suas posições político-culturais e de sua ativa defesa dos direitos humanos. Guevara se opõe abertamente a todos os tipos de violência. Através de fortes doses de humor urgente, ele constantemente confronta o poder dominante.

Palavras chave: música popular, contracultura, Jaime Guevara, artivismo, trova urbana.

\section{Introducción}

La personalidad de Jaime "Chamo" Guevara, se ha convertido prácticamente en una especie de símbolo, de ícono, de faro de la cultura ecuatoriana y evidentemente de la contracultura, representante por excelencia de la trova urbana, su popularidad se debe a 
sus canciones muy particulares, que abarcan géneros musicales como el rock, el blues, el country, llegando prácticamente a abordar también el universo musical de la música folclórica, entre otras. No podemos olvidar de hablar sobre su posición de artista comprometido y activista, a través de sus posicionamientos político-culturales y sobre todo su actitud como activo defensor de los derechos humanos, abiertamente declarado en contra de todo tipo de violencia, y lo más trascendente en su ponencia estético-musical es su constante crítica al poder dominante, al poder de turno, con sus fuertes dosis de humor terriblemente urticantes.

Anarquista desde que tiene uso de razón, vegetariano consumido, rockero por convicción, sus canciones nos hablan de una cotidianidad esencialmente urbana, una suerte de protesta social, su visión musical no se encierra en un género musical en especial, sino que navega en un universo de fusión musical, lo que caracteriza perfectamente su estilo musical.

Familiarmente es conocido como "El chamo Guevara", denominación adquirida durante sus años de juventud, también llamado "el cantor de contrabando", a causa de uno de sus discos que adquirió mucha popularidad "De contrabando".

Su actividad como artista comprometido, abarca tanto escenas nacionales como internacionales, así como escenarios improvisados, calles y cualquier lugar en donde su mensaje socio-musical es escuchado. Realmente un verdadero trovador de nuestro tiempo, el mismo que a fuerza de su voz y de su guitarra de "palo" ha sabido ganarse un sitio muy respetable en la vida musical ecuatoriana.

Los inicios de su aventura artística, los encontramos en los comienzos de los años 70, tocando en varios grupos de rock, creando en esos mismos años su propio grupo "La banda azul", teniendo como particularidad el hecho de que los temas que se cantaban ellos lo hacían en español, en una época en la que todo el rock se lo cantaba en inglés, así aparecieron versiones españolizadas de temas de Led Zeppelin, The Beatles, Back Sabbath, entre otros.

Su naciente actividad artística va a tomar un giro inesperado al final de los años 70 cuando durante la denominada "guerra de los cuatro reales", producida por el aumento de los pasajes urbanos por el gobierno militar de turno, cantando en las calles y en barrios populares, liderando las improvisadas barricadas con su guitarra en mano, es en curso de estos acontecimientos socio-políticos que Jaime Guevara decide consagrarse a una temática esencialmente social, sus canciones reflejarán los diferentes conflictos sociales, y la problemática de toda una sociedad injusta, y terriblemente represiva.

En los años 80, Jaime Guevara consolida su estilo musical y fortifica su mensaje como activista social, con los contenidos de sus canciones, cada vez más denunciantes frente al poder dominante.

Suma entonces -según propio testimonio- a sus iniciales influencias las de las coplas tradicionales ecuatorianas (carnaval de Guaranda, "sal quiteña", etc.), así como paralelamente- los cantares de los trovadores medievales y la canción francesa (poética y 
satírica) de los cantores -poetas de Francia- Georges Brassens y Jacques Brel, el folk social estadounidense (Bob Dylan, Woody Guthrie). Como resultado de la asimilación de corrientes surgieron composiciones de "fusión", particularmente entre el folklore ecuatoriano y el rock, muestra de ello presentó, en 1980, el recital "Folklor progresivoNueva Canción", junto al grupo Amauta. El contenido textual de sus canciones abarca creaciones infantiles, costumbrismo urbano, el amor y "retratos" de personajes y sucesos políticos; ello ha hecho que Guevara sea considerado un cronista musical. (música.com)

Entre las numerosas anécdotas, que el propio artista relata de sus encuentros con las fuerzas del orden, nos cuenta que en una ocasión su instrumento de trabajo, su guitarra fue confiscada como una evidencia, además recuerda con humor que más de una vez terminó encerrado en una perrera municipal. Guevara ha llegado a tener alrededor de 500 canciones de repertorio. Sus canciones más conocidas son:

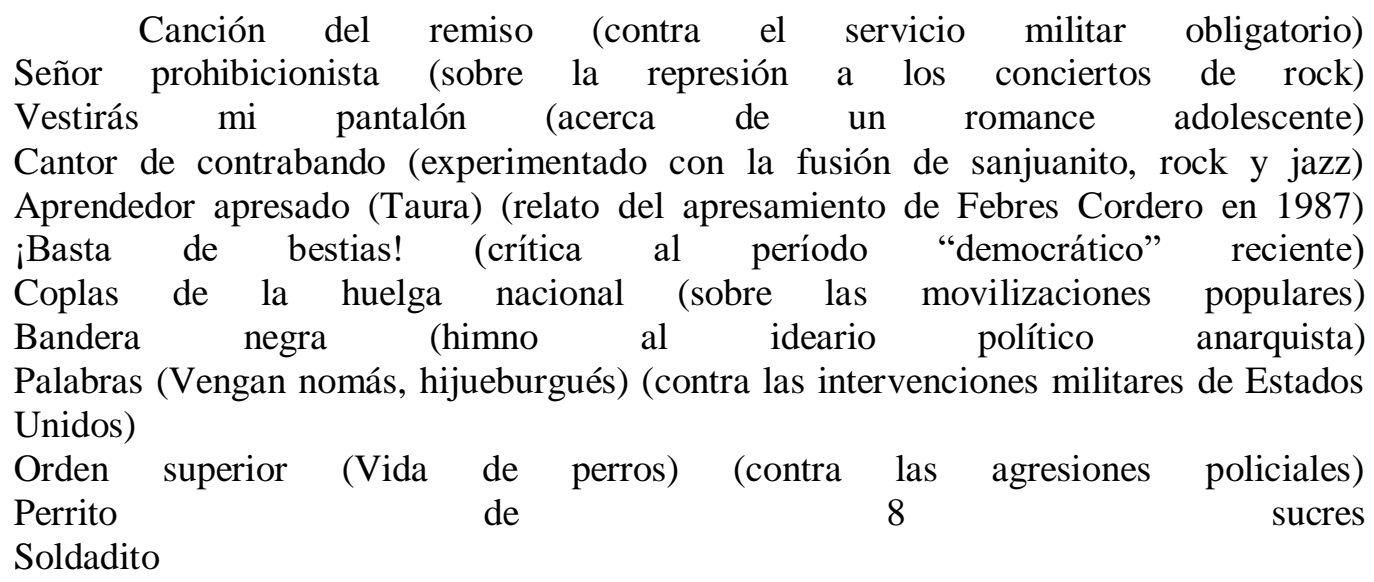

Sus canciones han servido de banda sonora para la película Entre Marx y una mujer desnuda (1997) y para el documental AVC: del sueño al caos (2007). Ha grabado un CD con las canciones de la primera producción cinematográfica (De contrabando), y una recopilación de temas en directo (En vivo 1977-1999). En 2001 fue copartícipe, junto con El Libertario de Venezuela, de la producción del CD internacional Notas de libertad que es una compilación de exponentes contemporáneos de la trova anarquista, la cual tuvo luego una edición de Chile.

Actualmente prepara el lanzamiento de una nueva producción discográfica (Palabras frontales) y de un cancionero con la letra y música de sus obras. Jaime Guevara ha decidido autoproducir sus dos discos por cuenta propia luego de que las disqueras locales le cerraran sus puertas debido a sus actividades políticas. (música.com)

$\mathrm{Su}$ papel como activista en defensa de los derechos humanos, se ha dirigido especialmente hacia los casos de personas desaparecidas, participando activamente en festivales de solidaridad. No podemos dejar de mencionar su activa participación en el caso de la desaparición de los hermanos Restrepo, luchando con su guitarra y sus textos para dilucidar el destino de estas víctimas de la represión oficial, Guevara participó por mas de 10 años en una batalla por aclarar este caso, el cual ha quedado en la impunidad hasta nuestros días. 
Los años 90 son caracterizados por una intensificación de su actividad vinculado a diferentes organizaciones ligadas a la defensa de los derechos humanos, notamente del movimiento "Prolibertad Artística Juvenil, Servicio de Paz y Justicia", creando una comisión para obtener el derecho a la objeción de conciencia, presentando propuestas al Congreso Nacional que en parte fueron aprobadas.

$\mathrm{Su}$ actividad no se ha limitado solamente al activismo social ni a la creación artística, sino que ha tenido un papel muy importante en el universo multimedial, siendo uno de los personajes en la película "Entre Marx y una mujer desnuda", personificando el rol de una poeta radical. Jaime Guevara igualmente a incursionado en el mundo de la producción literaria publicando un libro titulado "Lo que escribí en las paredes", haciéndose acreedor del premio José Peralta, en la categoría del periodismo testimonial.

El cantor de contrabando ha incursionado también en la composición musical ligada al teatro, como "El señor Puntilla, Robinson Crusoe, El milagro de los inocentes, entre otros.

Se han producido varios documentales, con duraciones diferentes sobre el trabajo socio-musical y sobre todo sobre su posición de resistencia a la política oficial, documentales que han recibido premios internacionales y proyectados tanto en Ecuador como en el extranjero (XV Encuentro Internacional de Editores Independientes y Ediciones Alternativas EDITA) en España. De la misma manera en Venezuela se proyectó el documental "Jaime Guevara un cantor de contrabando, trabajo audiovisual realizado por Any Alarcón dentro del cuadro de la segunda muestra de documentales independientes y videoactivismo, organizado por la organización Nelson Garrido. (música.com)

Escuchando al mismo Jaime Guevara sobre su actividad nos dice: "es una cosa de tripas, la indignación por el irrespeto a la vida me revienta", "Yo tengo una herramienta para denunciar, para llegar emocionalmente a la gente, mi canto. Esa indignación, esa fe que tengo en la defensa de la vida, en la guitarra toma cuerpo de resonancia, y cuando la gente lo oye, siento lo que piensa la enorme mayoría de nuestro pueblo, pero no lo puede decir".

En una de las entrevistas realizadas al cantor Jaime Guevara en enero del 2013 constatamos su posición ideológica al responder a las siguientes preguntas: ¿Qué papel cumple en democracia la protesta social?

"Un papel dinamizador, de avance de la sociedad contra todo tipo de represiones, porque no se puede permitir que un régimen de turno, el que fuere, implemente una serie de políticas económicas antipopulares”.

\section{¿Hacia dónde apunta esta protesta social?}

"A ponerle un alto a los abusos del poder". 


\section{¿Desde que Ecuador regresó a la democracia, cuál es el momento más crítico de los movimientos sociales en cuanto a represión?}

"El más crítico ha sido el del Gobierno de León Febres Cordero. Sin embargo, hoy se sigue aplicando represión, con mecanismos muy sutiles y, lo que es peor, a nombre de un supuesto socialismo, de una revolución".

\section{¿Cómo se ejerce actualmente esa represión?}

"Ya no se aplica el garrotazo, la tortura, la muerte oficial. Ahora te multan por hablar con un megáfono en la Plaza Grande, por pegar un afiche o te dan dos días de 'cana' por haber escrito un grafiti criticando al Régimen".

\section{¿Este Gobierno trata de criminalizar la protesta social?}

"Totalmente. Y no es el primero. Lo hizo también Febres Cordero, pero la diferencia es que el Gobierno actual ha logrado manipular el contenido del discurso canalizándolo hacia sus propios intereses. Un ejemplo es el movimiento roquero, es la primera ocasión en que hay un Gobierno que, fingiendo impulsarles".

\section{¿Por qué compara con frecuencia a este gobierno con el de Febres Cordero?}

"Porque si a este Gobierno se le permite cometer una tremenda injusticia con los 10 de Luluncoto, si se le permite la represión, vamos directito al mismo tipo de Régimen”.

\section{Pero el Gobierno dice que lo hace en aras de la estabilidad...}

"No vamos a permitir que el Régimen, so pretexto de reprimir el terrorismo, se convierta él mismo en terrorista. Ahora, bloquear una vía como mecanismo de protesta, este Gobierno lo convierte en un acto de terrorismo, de sabotaje".

\section{¿Pero no es una forma de garantizar la paz?}

"Garantizar la paz no es garantizar la paz de los cementerios. No garantizamos la libertad de pensamiento y de palabra amordazando a la gente".

¿Estamos viviendo en democracia?

"Una supuesta democracia que se ha transformado en 'dedocracia', y muchas veces en la 'dedocracia del gatillo'. Hay el caso de un chico de colegio que está prácticamente en estado vegetal (Édison Cosíos), cuando el gatillazo de un policía lanzabombas fue a parar en su cabeza".

Usted ha respaldado la protesta social, ha compuesto canciones, tiene temas contra el poder ¿Es usted terrorista?

“A ojos del Régimen y al paso que vamos no me llamaría la atención que se legisle como en la edad media a los juglares y trovadores. Esta inquisición puede remitirnos al silencio, a la violencia, al carcelazo". (fuente: revista digital la línea de fuego)

Citamos a continuación una de las canciones que nos parece muy representativa de la posición ideológica del "Chamo" Guevara: 
Se ha equivocado mayor...

"Danzábamos en el techo, por los quinientos abriles, cuando un montón de fusiles nos apuntó alrededor.

Se ha equivocado mayor, solo somos bailarines.

¿Por qué me sube al camión?

¿Por qué me empuja en el suelo?

¿Por qué me esposa los huesos?

¿Por qué encapucha mi frente?

Se ha equivocado teniente, solo soy titiritero.

Me roban todos los libros

y me preguntan a palos

si es que utilizo en asaltos mi careta y mi disfraz. Se equivocó capitán, solo soy actor de teatro. Luego el ministro explicó que era por ser guerrilleros, de las FARC o de Sendero, por lo que nos apresó. No mienta tanto señor, solo somos guitarreros. La moraleja del cuento es que los paracaidistas si quieren ver terroristas los miren pero en su espejo, y en cambio guarden respeto para el pueblo y sus artistas.

(Canción de Jaime Guevara, a propósito del apresamiento de artistas en octubre del 92)

\section{Conclusiones}

La actividad socio-cultural del artista y activista Jaime Guevara la podemos calificar como "Artivismo", que es una denominación resultado de la contracción de las palabras arte por una parte y activismo por otra, para categorizar al grupo de actividades artísticas que se desarrollan con el propósito determinado de promover o impulsar cambios radicales y concretos en la sociedad.

Estas actividades se basan en concentrar la atención a un tema ignorado o "tabú", realizando acciones para ocupar los espacios públicos, o manifestarse en contra de decisiones políticas que afectan a una parte significativa de la sociedad de forma directa $\mathrm{o}$ indirecta.

Los "artivistas" no se limitan a realizar solamente un arte callejero en todas sus variantes, sino que se ha producido de manera progresiva una nueva forma de comunicación, en la cual un mensaje es transmitido de una manera no lineal, sino de manera interactiva en donde el público tiene la posibilidad de actuar, responder y aportar al cambio social que el artista impulsa con su iniciativa. 
Aunque el "artivismo" es una actividad y una forma de expresión socio-artística que se realiza desde hace tiempo, pues el arte, en numerosas ocasiones ha servido como plataforma y vital herramienta de expresión, para realizar cambios significativos en una sociedad determinada.

El "artivismo" se manifiesta esencialmente donde la libertad se hallaba reprimida, como lo han sido las luchas independentistas, la búsqueda infatigable por la democracia, o la permanente lucha por el respeto de los derechos humanos.

La represión a la que nuestra sociedad ha estado sujeto a lo largo de toda la historia, ha provocado precisamente una necesidad de expresión, y el arte, aparte de buscar una estética o de servir para el escape de la realidad en forma de entretenimiento, tiene como funciones primordiales cuestionar, desestabilizar, informar y sobre todo educar, y a la vez, posee la capacidad de movilizar las masas y de impactar de manera colectiva a la sociedad.

\section{Bibliografía}

Gaby. (2 de febrero de 2019). ¿Cuál es la importancia del arte en la sociedad? Obtenido de Arte Escondido: https://www.artescondido.com/cual-es-la-importancia-delarte

La línea de fuego. (23 de enero de 2013). ENTREVISTA. JAIME GUEVARA: 'NO SE GARANTIZA LA LIBERTAD AMORDAZANDO A LA GENTE'. Obtenido de La línea de fuego. Revista digital: https://lalineadefuego.info/2013/01/23/entrevistajaime-guevara-no-se-garantiza-la-libertad-amordazando-a-la-gente/

Música.com. (s.f.). BIOGRAFÍA DE JAIME GUEVARA. Obtenido de Música.com: https://www.musica.com/letras.asp?biografia $=25661$ 